\title{
EDITORIAL
}

\section{Latest impact factor}

NPG Asia Materials (2016) 8, e290; doi:10.1038/am.2016.101; published online 22 July 2016

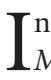
n the latest 2015 edition of Journal Citation Reports, NPG Asia Materials received a solid impact factor of 8.772. Even though this represents a 1.3 drop from the previous impact factor it still places the journal at number 13 among all 342 journals in the category of Materials Science (as categorized by Essential Science Indicators). Impact factor corrections and fluctuations are inevitable and have been experienced by other journals (including, most recently, Nature or Nature Photonics). This is even more true for a small-scale journal such as NPG Asia Materials. NPG Asia Materials started its existence by publishing invited review articles and has gradually introduced original research papers, contributed reviews and research highlights from 2012. The latest impact factor, thus, also reflects on the increasing portion of original research in the journal contents. At the same time, we are optimistic about the future of the journal including the trends of scientometric indicators. We have been receiving an increasing stream of good-quality submission, which has shown a particular rise in the 2016 calendar year. This gives us the possibility to select the best and most innovative research for publication in NPG Asia Materials. To choose for publication solid scientific research that shows novelty in physics or chemistry of materials does not necessarily translate into increased impact factor. There are trends and fashions in science, and we have occasionally seen manuscripts written in a sensational manner and rushed for publication often without a basic scientific background. We do not want to compromise the standards of scientific research in our journal for the sake of increasing scientometric indicators, and we also want to keep fairly covering all fields of materials science. The most important criteria for publishing in NPG Asia Materials remain fundamental novelty in physics or chemistry of materials, and we firmly believe that keeping these criteria will results in further successful growth of the journal which will also reflect in the impact factors to come. We want to thank all authors for choosing this journal as a venue for publication of their research, all reviewers for their unrewarded work and all readers for their continued support.

$$
\begin{array}{r}
\text { Martin Vacha, Jong-Hyun Ahn, Vasudevan Pillai Biju, } \\
\text { Tomoyasu Taniyama, Ikuyoshi Tomita, Shutao Wang } \\
\text { and Jihui Yang } \\
\text { Editors, NPG Asia Materials } \\
\text { E-mail: vacha.m.aa@m.titech.ac.jp }
\end{array}
$$

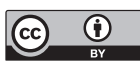

This work is licensed under a Creative Commons Attribution 4.0 International License. The images or other third party material in this article are included in the article's Creative Commons license, unless indicated otherwise in the credit line; if the material is not included under the Creative Commons license, users will need to obtain permission from the license holder to reproduce the material. To view a copy of this license, visit http:// creativecommons.org/licenses/by/4.0/

(C) The Author(s) 2016 